\title{
Ischemic and Postischemic Conditioning of the Myocardium in Clinical Practice: Challenges, Expectations and Obstacles
}

\author{
Efstathios K. Iliodromitis ${ }^{a}$ Ioanna Andreadou ${ }^{b}$ Konstantinos E. lliodromitis ${ }^{c}$ \\ Nikolaos Dagres ${ }^{a}$ \\ a Second Department of Cardiology, Medical School, Attikon University Hospital, and ${ }^{\text {b}}$ Department of \\ Pharmaceutical Chemistry, School of Pharmacy, University of Athens, Athens, Greece; 'Department of Cardiology, \\ Elisabeth Krankenhaus, Essen, Germany
}

\section{Key Words}

Preconditioning $\cdot$ Postconditioning $\cdot$ Perconditioning ·

Remote conditioning $\cdot$ Ischemia $\cdot$ Reperfusion injury

\begin{abstract}
Conditioning refers to endogenous mechanisms rendering the myocardium more tolerant against reperfusion injury. Application of brief ischemia-reperfusion cycles prior to the index ischemia has a beneficial effect and limits the infarct size. This is called preconditioning and is mainly mediated by activation of adenosine, bradykinin, opioid and other receptors, with subsequent activation of intracellular mediators leading to mitochondrial protection. A clinical equivalent of preconditioning is preinfarction angina. Benefits for the ischemic and reperfused myocardium are also provided by repetitive short-lived cycles of ischemia-reperfusion applied after the index ischemia. This is termed postconditioning, shares a common pathway with preconditioning, and is more useful and relevant in clinical practice. Finally, benefits are also derived from remote conditioning, i.e. ischemia applied in a remote vascular territory parallel with or immediately after the index myocardial ischemia. Several pharmacological interventions may interfere with these mechanisms leading to enhanced protection of the myocardium
\end{abstract}

and limitation of the infarct size. Despite the huge interest and the great body of evidence that verify the effectiveness of conditioning, clinical application has remained limited due to controversies over the appropriate intervention protocol, but also interference of medication, comorbidities and other factors that may enhance or blur the protective effect.

(c) 2014 S. Karger AG, Basel

\section{Main Characteristics of Conditioning}

Cardiovascular diseases are responsible for an increased mortality and morbidity in modern societies. Acute total obstruction of a coronary artery in the absence of collateral vessels capable of providing some perfusion inevitably leads to acute myocardial infarction. Timely restitution of coronary flow interrupts the wave of necrosis moving from the subendocardium to the subepicardium and results in a decrease of infarct size and improved patient survival and prognosis.

As early as 1986, research interest existed in interventions aiming at the limitation of the infarct size, which were not associated with opening of the occluded coronary artery and subsequent flow restitution. Those interventions were rather aiming at the activation of an endog-

\section{KARGER}

E-Mail karger@karger.com

www.karger.com/crd
(C) 2014 S. Karger AG, Basel

0008-6312/14/1292-0117\$39.50/0
Efstathios K. Iliodromitis, MD

Second Department of Cardiology, Medical School

Attikon University Hospital, Rimini 1, Haidari

GR-12462 Athens (Greece)

E-Mail iliodromitis@yahoo.gr 
enous protective mechanism rendering the myocardium more resistant to severe ischemia. This protective mechanism was termed preconditioning and was first described by Murry et al. [1] who, while investigating changes of the energy substrate in dogs at different times of ischemia, randomly found that the infarct size was significantly smaller if 4 repetitive cycles of ischemia-reperfusion of short duration ( $5 \mathrm{~min}$ ) were applied prior to the prolonged myocardial ischemia. The phenomenon of preconditioning was later confirmed in all experimental models in which it was applied, and the protection provided to the myocardium was found to be independent of the presence of collateral flow.

The first research period in preconditioning included the investigation of the natural course of this phenomenon, addressing questions such as: what is the duration and number of the short ischemia-reperfusion cycles, what is the ideal time point of their application before the prolonged ischemia, when is the protection decreased, when is it lost, when does it reappear and how long must the prolonged ischemia last if there is going to be a protective effect? This investigation of the natural history of the phenomenon showed that the protection is diminished and finally lost if there is a time interval of more than $2 \mathrm{~h}$ between the short and the prolonged ischemia [2-5], but paradoxically reappears spontaneously without any additional intervention $24 \mathrm{~h}$ later. This spontaneous reappearance of protection is named the second window of protection and confers a weaker but longer enduring protection compared with the first window of protection [6].

The next research period in preconditioning focused on the mechanism of protection, i.e. the identification of the receptors on the cell membrane, which activate a series of intracellular transmitters that take part in the protection [7-9]. The third research period targeted the identification of pharmacological agents and other factors or interventions, apart from brief myocardial ischemia, that confer the beneficial effect of preconditioning [10].

Parallel to research on an experimental level, there were also investigations on the existence and effectiveness of preconditioning in humans. Thus, in analogy to experimental studies, clinical studies investigated the natural history of preconditioning in humans and the reproduction of the beneficial effect through the use of drugs or interventions able to activate the receptors and the intracellular transmitters that had been identified previously [11]. The first simple model of preconditioning in man would be the patient with preinfarct angina who, according to the experimental data, should have a smaller infarct size compared to patients experiencing a myocardial in- farction without any prodromal symptoms. Indeed, there have been such positive findings in patients with preinfarct angina $[12,13]$, but we have to consider that the conditions in the clinical setting are not as precisely defined as in the experimental laboratory. Thus, the number and duration of the brief ischemia-reperfusion episodes, the time of their application before the complete occlusion of the coronary vessel, but also the duration of the following prolonged ischemia up to the reopening of the vessel, are precisely defined in the laboratory setting. In contrast, these requirements are not met in clinical observational studies unless these are well-scheduled clinical research trials. The not so stringent application of the experimental conditions and also the practical difficulties associated with ethical concerns resulted in the search for weaker and indirect endpoints, called surrogate endpoints, instead of hard ones, such as the reduction of mortality or infarct size. Such surrogate endpoints are, for instance, the reduction of pain intensity, of arrhythmias, of ST segment elevation on the surface ECG and the improvement of left ventricular contraction, etc. These are parameters that have been identified in experimental models and indirectly express the magnitude of the conferred protection [14-15]. The inability to achieve uniform conditions of application, and also the enthusiasm for positive results in clinical practice, has led to contradictory clinical results [16-18].

At this point, the mechanisms participating in myocardial protection need to be described. These mechanisms work at three levels: at the first level are the receptors at the cell surface, at the second level are the intracellular transmitters that activate and phosphorylate a series of intracellular factors, and at the third level is the final factor, which confers protection when activated. We will initially describe the first findings of the experimental studies on which the clinical studies were based, and thereafter the main elements of the underlying mechanisms as well as the most recent findings.

The cell receptors that activate the mechanism of preconditioning are mainly adenosine, bradykinin and opioid receptors [19-20]. Occupation of the bradykinin and opioid receptors by the respective stimulators activates a series of intracellular transmitters such as the kinases PI3, Akt and ERKs [20]. This is followed by an opening of the ATP-dependent potassium channels of the mitochondria, activation of the protein kinase $\mathrm{C}$ (PKC) as well as an intracellular increase of the free oxygen radicals during ischemia $[8,21]$. Adenosine activates PKC directly without involvement of these kinases. After PKC, a final factor is activated, which prevents the destruction of the mitochondrion and the subsequent cell death (fig. 1). 
Fig. 1. The mechanism of conditioning. Initial stimulation of adenosine, bradykinin or opioid receptors with participation of different kinases and mediators leads finally to protection of the mitochondria by preventing the opening of their $\mathrm{MPTP}$ pores. Pharmacological interventions may also activate these kinases resulting in $\mathrm{mi}$ tochondrial protection, while cyclosporine directly prevents mPTP opening. ROS = Reactive oxygen species; cGMP = cyclic guanosine monophosphate; $\mathrm{PKG}=$ protein kinase G.

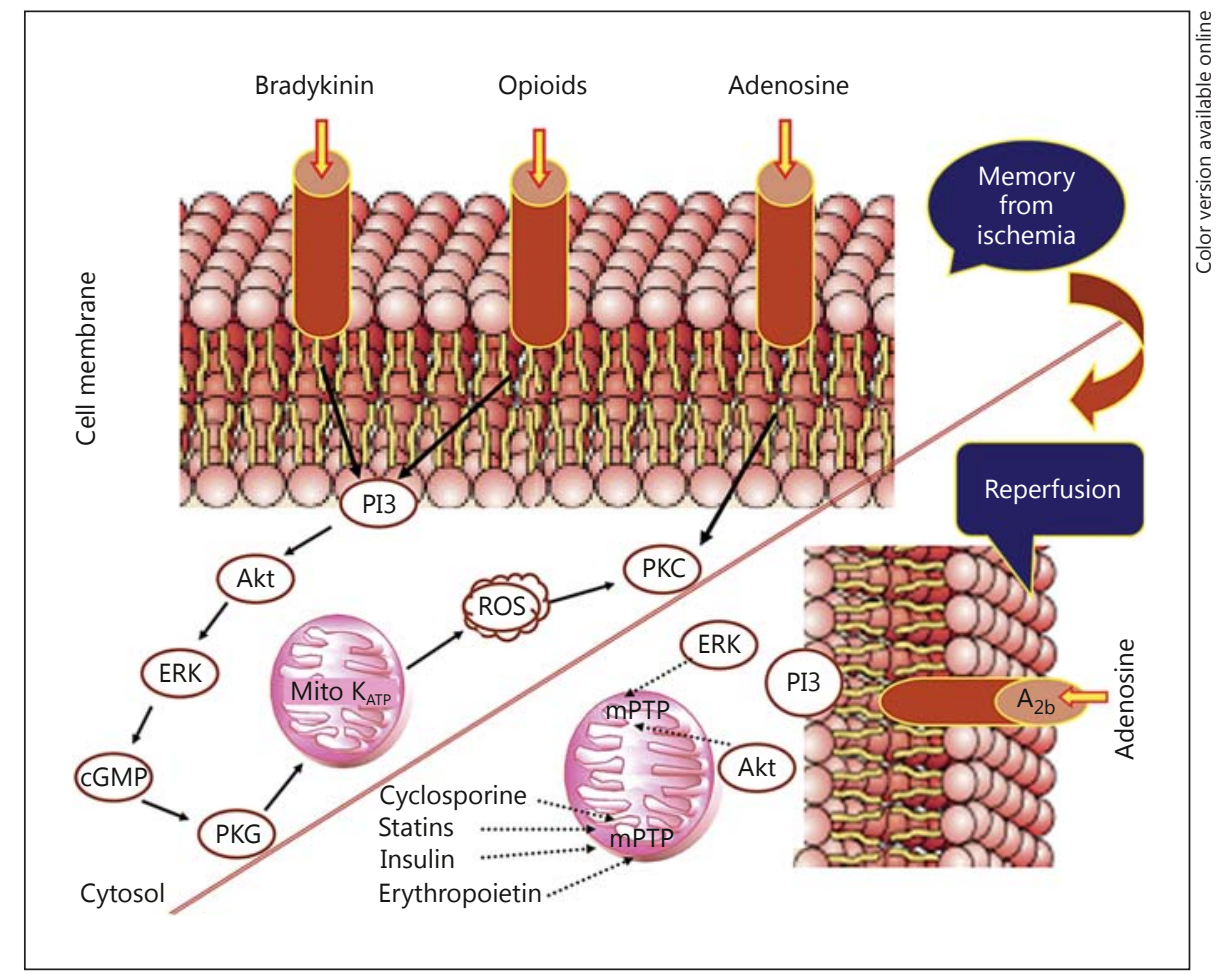

\section{Observational Trials}

As already mentioned, patients with preinfarct angina have smaller myocardial infarctions, less lethal arrhythmias and improved survival compared with those who have no prodromal symptoms $[13,21]$. Patients with preinfarct angina also demonstrate better angiographic results and coronary flow after thrombolysis [15]. Thus, clinical observations confirm the beneficial effect of prodromal symptoms in some of the patients with preinfarct angina due to its preconditioning function.

\section{Studies of Preconditioning Imitation: Reproduction in Man}

These studies concern patients undergoing serial exercise tests or repeated balloon inflations during coronary angioplasty [22, 23]. During these interventions, the first exercise test that demonstrates myocardial ischemia and the first balloon inflation with complete occlusion of the coronary artery, respectively, represent the first ischemic stimulation that activates the mechanism of protection, whereas the following exercise test or the following balloon inflations are considered the reference ischemia, which should cause a smaller damage as assessed by the various endpoints. Indeed, it has been shown that the duration of the second exercise test is longer than that of the first one with a greater double product and less pro- nounced ECG changes. Similarly, the balloon inflations during angioplasty that follow the first one cause a smaller ST elevation and less pain [23]. This is due to the fact that the first exercise test and the first balloon inflation act as preconditioning for the ones that follow. In addition, the existence and the effectiveness of the second window of protection have been confirmed with objective control methods in man. In particular, the existence and the effectiveness of delayed preconditioning have been shown with an exercise test at day one and a new exercise test or coronary angioplasty $24 \mathrm{~h}$ later [24].

\section{Pharmacological Interventions}

Adenosine infusion as an adjunct treatment to thrombolysis has provided interesting findings in the clinical trials AMISTAD [25] and AMISTAD II [26]. In the first of these trials, administration of adenosine in 236 patients with evolving myocardial infarction did not reduce the extent of necrosis in all patients, but did in those with large anterior infarctions. This was the first observation suggesting that the large area at risk is an important parameter that should be taken into account in the interpretation of the results. Another finding from the AMISTAD I trial was that the pharmacological intervention need not necessarily be applied before the index ischemia, but rather at the time of prolonged ischemia. The second AMISTAD trial 
included only patients with anterior infarction and showed a significant reduction of the infarct size as a result of administration of the appropriate drug dose. Nicorandil, a substance that activates the ATP-dependent potassium channels of the mitochondria and has been used in patients with stable and unstable angina, has also provided positive results regarding various endpoints [21, 27].

\section{Remote Preconditioning}

In 1993, it was demonstrated experimentally that brief ischemia can be applied not only to the coronary artery that is going to be occluded, but also to another coronary artery or to arteries of other organs resulting in a reduction of infarct size [28]. This phenomenon was named remote preconditioning and its effectiveness has been shown in various animal models as well as in organs other than the heart. Remote preconditioning has been applied with enthusiasm in humans, since it should provide protection of the ischemic myocardium after a temporary ischemia of another vascular territory. In clinical studies, the application of remote preconditioning has provided contradictory results mainly due to 'rather weak' and ambiguous endpoints, such as trivial changes of very low troponin levels [16-18]. However, it seems that in humans remote preconditioning activates the appropriate intracellular mediators that participate in the mechanism of protection [29].

\section{Postconditioning}

In 2003, the research group of Vinten-Johansen tested the application of very brief episodes of ischemia-reperfusion in dogs with a duration of only a few seconds immediately after the opening of the occluded coronary artery, and found that this intervention led to a significant reduction of the infarct size [30]. This phenomenon was termed postconditioning and underwent all the stages of control and research as preconditioning, with similar investigations regarding its efficacy in various animals, research protocols regarding its natural history, search for the responsible mechanism and administration of drugs mimicking it $[31,32]$, and also studies regarding its efficacy in man [32]. Obviously, postconditioning is much easier to implement and thus more useful and relevant in clinical practice because the induction of repeated brief ischemia-reperfusion bursts takes place at the time of the opening of an occluded coronary artery, e.g. during primary angioplasty, and not before the occlusion of the artery, which naturally cannot be predicted. The finding that intervention during revascularization, i.e. after the end of the prolonged ischemia, is beneficial proves the important contribution of the reperfusion damage to the final extent of the infarct zone [32]. During postconditioning, the very brief episodes of ischemia-reperfusion contribute to the progressive (and not abrupt) restitution of the low tissue $\mathrm{pH}$ to normal levels, to the restriction of oxygen free radicals, which also play a detrimental role during reperfusion, and to the prevention of calcium overload into the cell [33].

Interestingly, the search for the protective mechanism of postconditioning revealed after several years that preconditioning also limits the infarct size through a reduction of reperfusion damage $[32,33]$. The difference is that during preconditioning the myocardium is protected by direct interventions during the brief ischemia and reperfusion before the complete occlusion of the coronary artery, and also by cell 'memory' provided by brief preischemic interventions that activate the same series of factors, which reduce the reperfusion damage $[32,34]$. Regarding the myocardial protection provided by transient ischemia in the territory of a remote artery during evolving infarction, a series of experimental studies has demonstrated its efficacy, thus proving the existence of an effective and protective remote postconditioning [35-37].

Clinical studies and the applications of postconditioning in clinical practice have followed a similar course to that of preconditioning. Due to the nature of postconditioning, which is activated by very brief ischemia episodes during the first seconds of reperfusion, there can be no observational clinical studies as it is not possible to observe and evaluate brief ischemic episodes at the beginning of reperfusion in clinical practice. However, in analogy to preconditioning, there are clinical studies imitating and reproducing postconditioning with brief drug-induced episodes of ischemia-reperfusion or with application of ischemia to a remote artery.

Studies of Imitation-Reproduction of Postconditioning

The application of four additional balloon inflations with complete artery occlusion immediately after the opening of the culprit artery was tested during primary angioplasty in evolving myocardial infarction [38]. The duration of the additional balloon inflations as well as the intervals between them was $1 \mathrm{~min}$. This resulted in a reduction of the infarct size by $36 \%$ compared with the control group, as estimated by the release of biomarkers into the circulation. A large series of clinical studies followed with positive results regarding both infarct size and other control parameters, such as left ventricular function and 
remodeling, hospital and later prognosis, and other predefined endpoints $[33,39,40]$.

Thus, postconditioning exists and exerts an effective protective function on the postischemic myocardium in humans, significantly limiting the reperfusion damage. The beneficial effects were testified in many protocols of brief ischemia-reperfusion immediately after the opening of the artery with various times of application and various numbers of induced episodes in patients with STEMI, as well as in patients with significant coronary obstructions without ST segment elevation on the surface ECG $[33,39$, 40]. In addition to the reduction of infarct size, improvement of other endpoints was also demonstrated, such as reduction of the indicators of oxidative stress, improvement of myocardial microcirculation and long-term improvement of left ventricular function $[33,40]$.

\section{Confounders}

This section precedes the one referring to pharmacological interventions in order to make the use of particular pharmacological agents for the reproduction of postconditioning more comprehensible. An extremely large number of studies in various experimental models and under ex vivo, i.e. in an isolated beating heart outside of the animal, as well as in vivo conditions have investigated the intracellular changes and the series of events that participate in the protection of the myocardium after the application of brief ischemia-reperfusion episodes. Initially, it was recognized that there is in principle a common pathway in preconditioning and postconditioning with common receptors, ligands and several common intracellular pathways [33, 41]. This was both interesting and desirable, since many of the cell pathways of preconditioning had been already determined. Simultaneously, several novel intracellular transmitters and their isoforms, participating in one or more of the already known pathways, were identified.

Unfortunately for the daily clinical practice, research revealed a large number of cell transmitters and multiple intracellular pathways that either communicate with each other or result in the final beneficial factor by use of different pathways. This diversity creates a true labyrinth, the entrance of which includes the activators and binders of adenosine, bradykinin and opioid receptors, as described above, and also a series of other activators such as IL-6, NO, TNF- $\alpha$, the natriuretic peptides ANP and BNP and the growth hormones IGF-1 and FGF-2 [20, 42]. After initial stimulation, the intracellular pathways interact with each other with participation of the kinases PI3, Akt and
ERKs, the protein kinases $\mathrm{G}$ кal $\mathrm{C}$, cyclic GMP, the JAK kinase and the factors STAT 3 ka 5 [40, 42]. All these, together with free oxygen radicals inside the cell, finally lead to the protection of the mitochondria by preventing the opening of their pores (mPTP) $[32,43]$, resulting in salvage and survival of the cell. These data are mentioned not in order to illuminate all details of the complicated protective mechanism, but to demonstrate the size and complexity of the subject when research knowledge is transferred from the laboratory to humans, as well as to emphasize the difficulties encountered when trying to validate the beneficial effect and the achievement of protection by drugs acting as imitators of postconditioning. If we additionally take into account some isoforms of the intracellular transmitters, which may not be beneficial or may even be detrimental, or some receptor subtypes, then we might understand the size of the problem and the difficulties to validate protection in clinical practice.

\section{Pharmacological Interventions}

Insulin, statins and erythropoietin activate a series of kinases, which were mentioned before and which are named RISK from the initials of the words reperfusion injury salvage kinases [44]. These kinases protect the mitochondria by preventing the opening of their pores, which are named mPTP (mitochondrial permeability transition pores). This stops the entrance of factors that would change the osmolarity and the natural environment of the mitochondria leading to edema, destruction and finally death of the cell $[32,42]$. Erythropoietin, insulin and statins have been used with success in experimental studies with reduction of the infarct size. Cyclosporine protects the mitochondrion by direct inhibition of the opening of the MPTP pores without interference of the protective RISK kinases, and has been used successfully both experimentally and in patients with acute myocardial infarction undergoing primary angioplasty [32, 44, 45]. The extent of infarction in the group receiving intravenous cyclosporine was far smaller than in the control group; these results were similar to clinical findings in the setting of repeated brief ischemia. Consequently, the pharmacological intervention with cyclosporine exerts a beneficial effect and validates the protective mechanism of postconditioning in humans [45]. The whole mechanism of conditioning is summarized in figure 1.

\section{Remote Postconditioning}

In analogy to preconditioning, experimental studies sought for and found a beneficial effect of remote intermittent brief shots of ischemia application as in postcon- 
Fig. 2. The hypothesis of remote conditioning. A remote organ ischemia, such as ischemia of the upper or lower limb induced, for example, by inflation of a cuff manometer, leads to a release of conditioning and humoral agents and activation of neural pathways resulting in protection of the target organs, including the heart, kidneys, liver and brain.

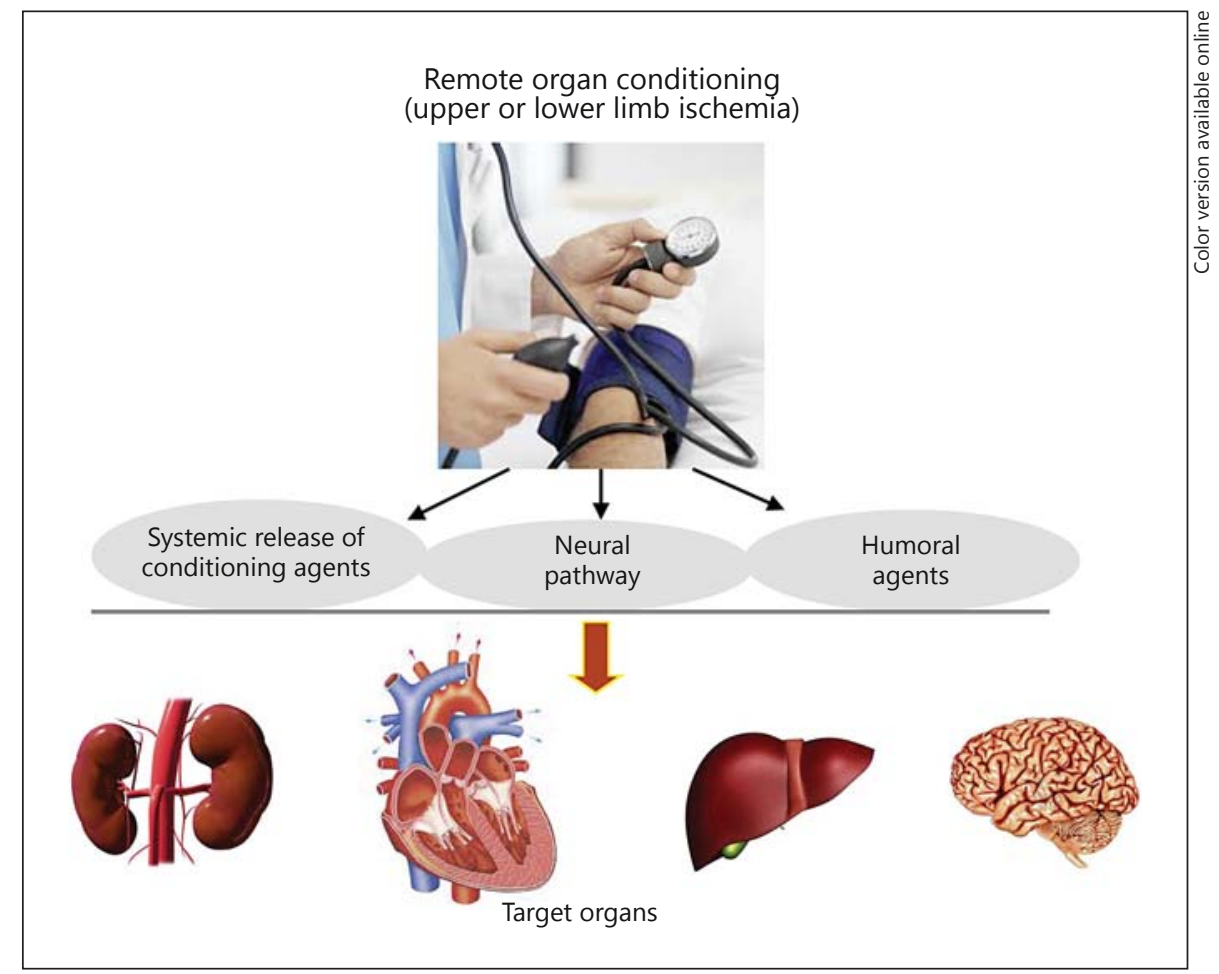

ditioning. In some of them the brief episodes of remote ischemia took place immediately after the opening of the coronary artery [36], while in others the remote ischemia took place during [35] or during and after [46] the period of occlusion of the coronary artery. This is termed perconditioning.

The experimental findings of remote postconditioning and of perconditioning were very promising regarding their application in humans. It became clear that during evolving myocardial infarction there exists a possibility to apply perconditioning, i.e. temporary ischemia in some other vessel remote from the coronary circulation, with the expectation of achieving a reduction of infarct size. Indeed, in the ambulance during the transportation of patients to hospital, the group of Bøtker et al. [47] applied the inflation of a cuff manometer at the brachial artery to high pressures in order to achieve temporary peripheral ischemia and subsequent reperfusion of the upper extremity. This intervention resulted in significant reduction of necrosis in patients with acute anterior myocardial infarction. Similar beneficial effects with similar interventions have also been found in other human organs [33]. The hypothesis of remote conditioning is presented in figure 2.

\section{The Pandora Box}

According to the existing experimental and clinical data, there exists a mechanism that has been proven to protect the myocardium under specific circumstances. However, these findings are not consistent or may even be contradictory in several cases of daily clinical practice $[48,49]$. In particular, the appropriate number and ideal duration of each brief episode of ischemia-reperfusion in man in order to achieve a beneficial effect are questioned [50]. There are also uncertainties regarding the response of elderly patients compared with younger ones, of patients with hypertension, hypercholesterolemia or diabetes, the effect of gender and age, and finally the role of progressive restitution of flow compared with abrupt opening of the artery $[40,41,51]$. The double role of free oxygen radicals, namely beneficial during sustained ischemia and detrimental upon reperfusion, is an additional factor that contributes to the difficulty to evaluate respective results and to apply effective postconditioning in clinical practice on a wide scale [42]. It should also be considered that many patients already receive pharmacological treatment for coronary artery disease or for risk factors. Some of these drugs may enhance while other neutralize the beneficial effect of 'conditioning' [42, 45, $52]$. This is an additional reason that so many years after 
the first descriptions and despite the evidence that this protective mechanism works in humans, its application has not been adopted by international guidelines for treatment of acute myocardial infarction.

Furthermore, to evaluate the result, one should take into account not only the final extent of the infarct, but also the area that was subjected to risk, since experimental and clinical data have shown that the extent of infarction is proportional to the extent of the area that was subjected to ischemic risk. A small area at risk is associated with small and consequently not recognizable protection [45, 47]. Thus, the ratio of necrosis to the area at risk should be calculated; this poses difficulties in clinical practice and a precise calculation demands additional imaging with echocardiography or performing ventriculography in the catheterization laboratory, with radioisotopes or with magnetic resonance imaging. Nevertheless, it appears that any form of conditioning is effective in humans, but the above-mentioned confounders should always be considered with caution.

Despite the positive findings in the initial clinical study of local postconditioning during primary angioplasty in humans [38], similar protocols from other groups with a small [48] or large number of patients [49] failed to show any similar benefit, putting its effectiveness in dispute. Compared to local application of balloon inflation in primary percutaneous coronary intervention, remote ischemic conditioning seems to provide more stable and reproducible results when applied in evolving myocardial infarction, very similar to the first clinical study findings [47] according to the findings of the same [53] and other groups [54].

The effectiveness of conditioning is also questionable during cardiothoracic surgery. Some studies are more promising [55], but others, with very similar [56] or even stronger conditioning protocols [57] failed to reconfirm the initial enthusiasm. Two ongoing large multicenter clinical trials, the ERICCA (NCT01247545) [58] and RIPHeart trials (NCT01067703) [59], will probably shed light on the outcome of patients who undergo coronary artery bypass surgery and who are subjected to remote conditioning.

Despite the encountered difficulties and the lack of proof of endogenous protection in humans, there is optimism that innocent and safe interventions remote from the myocardium, as well as appropriate pharmacological interventions, will add a very useful tool to our armamentarium for the reduction of myocardial damage [47]. The validation in clinical practice requires prudence and patience. Trivial reduction of some biomarkers or equivocal surrogate endpoints should be interpreted cautiously.
It should be taken into account that some differences are related to the total ischemic burden, to the mode of ischemia, i.e. elective angioplasty, evolving myocardial infarction and cardiothoracic surgery, etc., and to the therapeutic interventions. All these thoughts and the various mechanical or pharmaceutical interventions are extensively presented, describing the chances, challenges and concerns related to the translation of the experimental findings into clinical practice $[60,61]$. Finally, some divergent results may be due to genetic differences of the study population (Asians vs. Europeans or Americans) and to the ability of some experienced groups of investigators to apply appropriate interventions, providing consistently positive results. Research is ongoing and recent experimental data provide one more optimistic message that postconditioning may be applied not only directly after the opening of the occluded artery but also somewhat later.

In conclusion, the mechanisms of endogenous protection work effectively in humans and may be reproduced in daily clinical practice. They reduce the final infarct size by restricting the reperfusion injury, which contributes approximately $40 \%$ to the final infarct size. They are reproduced under particular circumstances with drugs such as cyclosporine, adenosine, opioids, inhibitors of the angiotensin-converting enzyme, but also insulin, statins and erythropoietin. There are clear indications that in humans the application of remote ischemia during evolving infarction is beneficial. The demonstration of a beneficial effect requires a large ischemic area of the myocardium at risk and is therefore evident only in large infarcts. Current interventions, such as primary angioplasty, novel antiplatelet drugs and $\beta$-blockers reduce significantly the infarct size and prevent the demonstration of additional protection. Long-term patient therapy with inhibitors of the angiotensin-converting enzyme, nitrates, statins, $\beta$-blockers, oral antidiabetics and insulin induce or inhibit conditioning and blur its effects. Comorbidities affect the level of protection. The endogenous mechanisms of protection act also in other organs, such as the kidneys, liver, brain and spinal cord. Negative studies should be interpreted with caution in order not to repeat clinical protocols that cost time and money.

\section{Conflict of Interest}

There are no financial or other interests which might pose a conflict of interest. 


\section{References}

1 Murry CE, Jennings RB, Reimer KA: Preconditioning with ischemia: a delay of lethal cell injury in ischemic myocardium. Circulation 1986;74:1124-1136.

2 van Winkle DM, Thornton JD, Downey JM: Cardioprotection from ischemic preconditioning is lost following prolonged reperfusion in the rabbit. Coron Artery Dis 1991;2: 613-619.

-3 Iliodromitis EK, Kremastinos DT, Katritsis DG, Papadopoulos CC, Hearse DJ: Multiple cycles of preconditioning cause loss of protection in open-chest rabbits. J Mol Cell Cardiol 1997;29:915-920.

4 Li Y, Kloner RA: Cardioprotective effects of ischemic preconditioning can be recaptured after they are lost. J Am Coll Cardiol 1994;23: 470-474.

$>5$ Iliodromitis EK, Papadopoulos C, Paraskevaidis IA, Kyriakides ZS, Flessa C, Kremastinos DT: Protection from preconditioning can be reinstated at various reperfusion intervals. Cardiovasc Drugs Ther 1996;10:341-346.

-6 Yellon DM, Baxter GF: A 'second window of protection' or delayed preconditioning phenomenon: future horizons for myocardial protection? J Mol Cell Cardiol 1995;27:10231034.

$>7$ Liu GS, Thornton J, van Winkle DM, Stanley AWH, Olsson RA, Downey JM: Protection against infarction afforded by preconditioning is mediated by $\mathrm{A} 1$ adenosine receptors in rabbit heart. Circulation 1991;84:350-356.

$>8$ Liu Y, Ytrehus K, Downey JM: Evidence that translocation of protein kinase $\mathrm{C}$ is a key event during ischemic preconditioning of rabbit myocardium. J Mol Cell Cardiol 1994; 26:661-668

$>9$ Schulz R, Cohen MV, Behrends M, Downey JM, Heusch G: Signal transduction of ischemic preconditioning. Cardiovasc Res 2001; 52:181-198.

10 Parratt JR: Possibilities for the pharmacological exploitation of ischemic preconditioning. J Mol Cell Cardiol 1995;27:991-1000.

$>11$ Leesar MA, Stoddard MF, Manchikalapudi S, Bolli R: Bradykinin-induced preconditioning in patients undergoing coronary angioplasty. J Am Col Cardiol 1999;34:639-650.

-12 Kloner RA, Shook T, Przyklenk K, Davis VG, Junio L, Matthews RV, Burstein S, Gibson M, Poole WK, Cannon CP, et al: Previous angina alters in hospital outcome in TIMI 4: a clinical correlate to preconditioning? Circulation 1995;91:37-45.

-13 Ottani F, Galvani M, Ferrini D, Sorbello F, Limonetti P, Pantoli D, Rusticali F: Prodromal angina limits infarct size: a role for ischemic preconditioning. Circulation 1995;91: 291-297.

14 Cohen MV, Liu GS, Downey JM: Preconditioning causes improved wall motion as well as smaller infarcts after transient coronary occlusion in rabbits. Circulation 1991;84:341349 .
15 Ishihara M, Sato H, Tateishi H, Kawagoe T, Shimatani Y, Kurisu S, Sakai K, Ueda K: Implications of prodromal angina pectoris in anterior wall acute myocardial infarction: acute angiographic findings and long-term prognosis. J Am Coll Cardiol 1997;30:970-975.

16 Iliodromitis EK, Kyrzopoulos S, Paraskevaidis IA, Kolocassides KG, Adamopoulos S, Karavolias G, Kremastinos DT: Increased C reactive protein and cardiac enzyme levels after coronary stent implantation: is there protection by remote ischaemic preconditioning? Heart 2006;92:1821-1826.

17 Hoole SP, Heck PM, Sharples L, Khan SN, Duehmke R, Densem CG, Clarke SC, Shapiro LM, Schofield PM, O’Sullivan M, Dutka DP: Cardiac Remote Ischemic Preconditioning in Coronary Stenting (CRISP Stent) Study: a prospective, randomized control trial. Circulation 2009;119:820-827.

18 Rahman IA, Mascaro JG, Steeds RP, Frenneaux MP, Nightingale $P$, Gosling $P$, Townsend P, Townend JN, Green D, Bonser $\mathrm{RS}$ : Remote ischemic preconditioning in human coronary artery bypass surgery. Circulation 2010;122(suppl 1):S53-S59.

19 Oldenburg O, Qin Q, Krieg T, Yang XM, Philipp S, Critz SD, Cohen MV, Downey JM: Bradykinin induces mitochondrial ROS generation via NO, cGMP, PKG, and mitoKATP channel opening and leads to cardioprotection. Am J Physiol Heart Circ Physiol 2004; 286:H468-H476.

20 Crisostomo PR, Wairiuko GM, Wang M, Tsai BM, Morrell ED, Meldrum DR: Preconditioning versus postconditioning: mechanisms and therapeutic potentials. J Am Coll Surg 2006;202:797-812.

21 Kloner RA, Rezkalla SH: Preconditioning, postconditioning and their application to clinical cardiology. Cardiovasc Res 2006;70: 297-307.

22 Edwards RJ, Redwood SR, Lambiase PD, Tomset E, Rakhit RD, Marber MS: Antiarrhythmic and anti-ischaemic effects of angina in patients with and without coronary collaterals. Heart 2002;88:604-610.

23 Laskey WK: Beneficial impact of preconditioning during PTCA on creatinine kinase release. Circulation 1999;99:2085-2099.

24 Iliodromitis EK, Koutelou M, Paraskevaidis IA, Theodorakos A, Farmakis D, Tsoutsanis J, Kremastinos DT: Treadmill exercise test with dual isotope scintigraphy documents the second window of protection in humans. Atherosclerosis 2008;198:122-128.

25 Mahaffey KW, Puma JA, Barbagelata NA, DiCarli MF, Leesar MA, Browne KF, Eisenberg PR, Bolli R, Casas AC, Molina-Viamonte V, Orlandi C, Blevins R, Gibbons RJ, Califf RM, Granger CB: Adenosine as an adjunct to thrombolytic therapy for acute myocardial infarction: results of a multicenter, randomized, placebo-controlled trial: the Acute Myocardial Infarction Study of Adenosine
(AMISTAD) trial. J Am Coll Cardiol 1999;34: 1711-1720.

26 Ross AM, Gibbons RJ, Stone GW, Kloner RA, Alexander RW: A randomized, double-blinded, placebo-controlled multicenter trial of adenosine as an adjunct to reperfusion in the treatment of acute myocardial infarction (AMISTAD II). J Am Coll Cardiol 2005;45: 1775-1780.

27 IONA Study Group: Effect of nicorandil on coronary events in patients with stable angina: the Impact of Nicorandil in Angina Randomized trial. Lancet 2002;359:1269-1275.

28 Przyklenk K, Bauer B, Ovize M, Kloner RA, Whittaker P: Regional ischemic preconditioning protects remote virgin myocardium from subsequent sustained coronary occlusion. Circulation 1993;87:893-899.

29 Heusch G, Musiolik J, Kottenberg E, Peters J, Jakob H, Thielmann M: STAT5 activation and cardioprotection by remote ischemic preconditioning in humans. Circ Res 2012;110: 111-115.

30 Zhao ZQ, Corvera JS, Halkos ME, Kerendi F, Wang NP, Guyton RA, Vinten-Johansen J: Inhibition of myocardial injury by ischemic postconditioning during reperfusion: comparison with ischemic preconditioning. Am J Physiol Heart Circ Physiol 2003;285:H579-H588.

31 Iliodromitis EK, Georgiadis M, Cohen MV, Downey JM, Bofilis E, Kremastinos DT: Protection from postconditioning depends on the number of short ischemic insults in anesthetized pigs. Basic Res Cardiol 2006;101: 502-507.

32 Yellon DM, Hausenloy DJ: Myocardial reperfusion injury. New Engl J Med 2007;357: 1121-1135.

33 Schwartz Longarce L, Kloner RA, Arai AE, Baines CP, Bolli R, Braunwald E, Downey J, Gibbons RJ, Gottlieb RA, Heusch G, Jennings RB, Lefer DJ, Mentzer RM, Murphy E, Ovize M, Ping P, Przyklenk K, Sack MN, Vander Heide RS, Vinten-Johansen J, Yellon DM, National Heart, Lung, and Blood Institute, $\mathrm{Na}$ tional Institutes of Health: New horizons in cardioprotection: recommendations from the 2010 National Heart, Lung, and Blood Institute Workshop. Circulation 2011;124:1172-1179.

-34 Downey JM, Cohen MV: Reducing infarct size in the setting of acute myocardial infarction. Prog Cardiovasc Dis 2006;48:363-371.

$>35$ Kerendi F, Kin H, Halkos ME, Jiang R, Zatta AJ, Zhao ZQ, Guyton RA, Vinten-Johansen J: Remote postconditioning: brief renal ischemia and reperfusion reduces myocardial infarct size via endogenous activation of adenosine receptors. Basic Res Cardiol 2005;100: 404-412.

36 Andreka G, Vertesaljai M, Szantho G, Font G, Piroth Z, Fontos G, Juhasz ED, Szekely L, Szelid Z, Turner MS, Ashrafian H, Frenneaux MP, Andreka P: Remote ischaemic postconditioning protects the heart during acute myocardial infarction in pigs. Heart 2007;93:749-752. 
37 Gritsopoulos G, Iliodromitis EK, Zoga A, Farmakis D, Demerouti E, Papalois A, Paraskevaidis IA, Kremastinos DT: Remote postconditioning is more potent than classic postconditioning in reducing the infarct size in anesthetized rabbits. Cardiovasc Drugs Ther 2009;23:193-198.

38 Staat P, Rioufol G, Piot C, Cottin Y, Cung TT, L'Huillier I, Aupetit JF, Bonnefoy E, Finet G, André-Fouët X, Ovize M: Postconditioning the human heart. Circulation 2005; 112:21432148.

39 Iliodromitis EK, Paraskevaidis IA, Fountoulaki K, Farmakis D, Andreadou I, Antoniadis A, Ikonomidis I, Leftheriotis D, Kremastinos DT: Staccato reperfusion prevents reperfusion injury in patients undergoing coronary angioplasty: a 1-year follow-up pilot study. Atherosclerosis 2009;204:497-502.

-40 Hausenloy DJ, Baxter G, Bell R, Bøtker HE, Davidson SM, Downey J, Heusch G, Kitakaze M, Lecour S, Mentzer R, Mocanu MM, Ovize M, Schulz R, Shannon R, Walker M, Walkinshaw G, Yellon DM: Translating novel strategies for cardio-protection: the Hatter Workshop Recommendations. Basic Res Cardiol 2010;105:677-686.

41 Hausenloy DJ, Yellon DM: Preconditioning and postconditioning: new strategies for cardioprotection. Diabetes Obes Metab 2008; 10: 451-459.

42 Burley DS, Baxter GF: Pharmacological targets revealed by myocardial postconditioning. Curr Opinion Pharmacol 2009;9:177188 .

-43 Boengler K, Hilfiker-Kleiner D, Heusch G, Schulz R: Inhibition of permeability transition pore opening by mitochondrial STAT3 and its role in myocardial ischemia/reperfusion. Basic Res Cardiol 2010:105:771-785.

44 Hausenloy DJ, Yellon DM: Reperfusion injury salvage kinase signalling: taking a RISK for cardioprotection. Heart Fail Rev 2007;12: 217-234.

45 Piot C, Croisille P, Staat P, Thibault H, Rioufol G, Mewton N, Elbelghiti R, Cung TT, Bonnefoy E, Angoulvant D, Macia C, Raczka F, Sportouch C, Gahide G, Finet G, AndréFouët X, Revel D, Kirkorian G, Monassier JP, Derumeaux G, Ovize M: Effect of cyclosporine on reperfusion injury in acute myocardial infarction. N Engl J Med 2008;359:473481.

-46 Hausenloy DJ, Iliodromitis EK, Andreadou I, Papalois A, Gritsopoulos G, Anastasiou-Nana M, Kremastinos DT, Yellon DM: Investigating the signal transduction pathways underlying remote ischemic conditioning in the porcine heart. Cardiovasc Drugs Ther 2012;26: 87-93.
47 Bøtker HE, Kharbanda R, Schmidt MR, Bøttcher M, Kaltoft AK, Terkelsen CJ, Munk $\mathrm{K}$, Andersen NH, Hansen TM, Trautner S, Lassen JF, Christiansen EH, Krusell LR, Kristensen SD, Thuesen L, Nielsen SS, Rehling $\mathrm{M}$, Sørensen HT, Redington AN, Nielsen TT: Remote ischaemic conditioning before hospital admission, as a complement to angioplasty, and effect on myocardial salvage in patients with acute myocardial infarction: a randomized trial. Lancet 2010; 375:727-734.

48 Freixa X, Bellera N, Ortiz-Pérez JT, Jiménez M, Paré C, Bosch X, De Caralt TM, Betriu A, Masotti M: Ischaemic postconditioning revisited: lack of effects on infarct size following primary percutaneous coronary intervention. Eur Heart J 2012;33:103-112.

49 Hahn JY, Song YB, Kim EK, Yu CW, Bae JW, Chung WY, Choi SH, Choi JH, Bae JH, An KJ, Park JS, Oh JH, Kim SW, Hwang JY, Ryu JK, Park HS, Lim DS, Gwon HC: Ischemic postconditioning during primary percutaneous coronary intervention: the effects of postconditioning on myocardial reperfusion in patients with ST-segment elevation myocardial infarction (POST) randomized trial. Circulation 2013;128:1889-1894.

50 Skyschally A, van Caster P, Iliodromitis EK, Schulz R, Kremastinos DT, Heusch G: Ischemic postconditioning: experimental models and protocol algorithms. Basic Res Cardiol 2009;104:469-483.

51 Okamoto F, Allen BS, Buckberg GD, Bugyi H, Leaf J: Reperfusion conditions: importance of ensuring gentle versus sudden reperfusion during relief of coronary occlusion. J Thorac Cardiovasc Surg 1986;92:613-620.

52 Iliodromitis EK, Andreadou I, Prokovas E, Zoga A, Farmakis D, Fotopoulou T, Ioannidis K, Paraskevaidis IA, Kremastinos DT: Simvastatin in contrast to postconditioning reduces infarct size in hyperlipidemic rabbits: possible role of oxidative/nitrosative stress attenuation. Basic Res Cardiol 2010;105:193203.

53 Sloth AD, Schmidt MR, Munk K, Kharbanda RK, Redington AN, Schmidt M, Pedersen L, Sørensen HT, Bøtker HE, CONDI Investigators: Improved long-term clinical outcomes in patients with ST-elevation myocardial infarction undergoing remote ischaemic conditioning as an adjunct to primary percutaneous coronary intervention. Eur Heart J 2014; 35:168-175.

54 Crimi G, Pica S, Raineri C, Bramucci E, De Ferrari GM, Klersy C, Ferlini M, Marinoni B, Repetto A, Romeo M, Rosti V, Massa M, Raisaro A, Leonardi S, Rubartelli P, Oltrona Visconti L, Ferrario M: Remote ischemic post-conditioning of the lower limb during percutaneous coronary intervention safely reduces enzymatic infarct size in anterior myocardial infarction. JACC Cardiovasc Interv 2013;6:1055-1063.

55 Thielman M, Kottenberg E, Kleinbongard P, Wendt D, Gedik N, Pasa S, Price V, Tsagakis K, Neuhäuser M, Peters J, Jakob H, Heusch G: Cardioprotective and prognostic effects of remote ischaemic preconditioning in patients undergoing coronary artery bypass surgery: a single-center randomised, double-blind, controlled trial. Lancet 2013;382:597-604.

56 Karuppasamy P, Chanbey S, Dew T, Musto R, Sherwood R, Desai J, John L, Shah AM, Marber MS, Kunst G: Remote intermittent ischemia before coronary bypass graft surgery: a strategy to reduce injury and inflammation? Basic Res Cardiol 2011;106:511-519.

57 Hong DM, Lee EH, Kim HJ, Min JJ, Chin JH, Choi DK, Bahk JH, Sim JY, Choi IC, Jeon Y: Does remote ischaemic preconditioning with postconditioning improve clinical outcomes of patients undergoing cardiac surgery? Remote ischaemic preconditioning with postconditioning trial. Eur Heart J 2014;35:176183.

58 Hausenloy DJ, Candilio L, Laing C, Kunst G, Pepper J, Kolvekar S, Evans R, Robertson S, Knight R, Ariti C, Clayton T, Yellon DM, ERICCA Trial Investigators: Effect of remote ischemic preconditioning on clinical outcomes in patients undergoing coronary artery bypass graft surgery (ERICCA): rationale and study design of a multi-centre randomized double-blinded controlled clinical trial. Clin Res Cardiol 2012;101:339-348.

59 Meybohm P, Zacharowski K, Cremer J, Roesner J, Kletzin F, Schaelte G, Felzen M, Strouhal U, Reyher C, Heringlake M, Schön J, Brandes I, Bauer M, Knuefermann P, Wittmann M, Hachenberg T, Schilling T, Smul T, Maisch S, Sander M, Moormann T, Boening A, Weigand MA, Laufenberg R, Werner C, Winterhalter M, Treschan T, Stehr SN, Reinhart K, Hasenclever D, Brosteanu O, Bein B, RIP Heart-Study Investigator Group: Remote ischaemic preconditioning for heart surgery: the study design for a multi-center randomized double-blinded controlled clinical trial - the RIPHeart-Study. Eur Heart J 2012;33: 1423-1426.

60 Heusch G: Cardioprotection: chances and challenges of its translation to the clinic. Lancet 2013;381:166-175.

61 Gerczuk PZ, Kloner RA: An update on cardioprotection: a review of the latest adjunctive therapies to limit myocardial infarction size in clinical trials. J Am Coll Cardiol 2012;59: 969-978. 